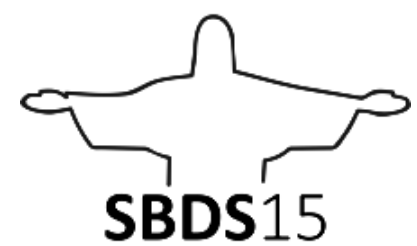

\title{
Os Living Labs como plataforma de metaprojetação, sustentabilidade e inovação social
}

\author{
Aron Krause Litvin \\ PPG Design Unisinos \\ aron@estudionomade.com.br \\ Carlo Franzato \\ PPG Design Unisinos \\ cfranzato@unisinos.br \\ Gustavo Borba \\ PPG Design Unisinos \\ gborba@unisinos.br \\ Karine Freire \\ PPG Design Unisinos \\ kmfreire@unisinos.br
}

\begin{abstract}
Resumo: O caminho do design rumo à sustentabilidade demanda inovação nos modelos de organização e nos processo de projeto. Os Living Labs representam uma possibilidade para desenvolvê-los e praticá-los com a participação de usuários. O artigo apresenta um estudo teórico sobre a relação que é desenvolvível entre Living Labs e metadesign. No processo de habilitação dos usuários à criatividade e ao design, os Living Labs utilizam o princípio de abertura próprio do metadesign. Como resultado, o artigo desdobra o potencial de inovação social ínsito nesta relação.
\end{abstract}

Palavras-chave: Living Labs, Inovação, Design Estratégico, Metaprojeto

\begin{abstract}
The way of design towards sustainability demand innovation in organizational models and design process. The Living Labs represent a chance to develop them and practice them with the participation of users. The article presents a theoretical study between the relationship of Living Labs and metadesign. In the enabling process of the users to creativity and design, Living Labs use the own metadesign principle of openness. As part of results, the article approaches the social innovation potencial on this relationship.
\end{abstract}


Keywords: Living Labs, Innovation, Strategic Design, Metadesign

\section{INTRODUÇÃO}

Com a crise dos nossos modelos de desenvolvimento hipertróficos, há necessidade de encontrar soluções aos problemas da vida cotidiana nos centros urbanos que, em linha com a Declaração do Rio (UNCED, 1992), não comprometam as possibilidades das gerações futuras. Tais problemas convivem com o paradigma da complexidade, na medida em que há incerteza e incompletude do conhecimento que dê conta em definitivo de suas repostas. Trata-se de um percurso incansável, praticamente sem fim, multidimensional que abraça a incerteza. Complexidade é um tecido de acontecimentos, ações, interações, retroações, determinações, acasos, que constituem nosso mundo fenomênico (MORIN, 2003).

Os modelos organizacionais e os processos de projeto implementados pelas organizações governamentais, não governamentais ou da iniciativa privada não conseguem expressar soluções deste tipo. No horizonte da co-criação, porém, surgem novas processualidades pelas quais as pessoas se autoorganizamse para responder às suas próprias necessidades através de diferentes configurações.

A propósito, Manzini (2014) refere-se "a transformações no modo como indivíduos ou comunidades agem para resolver seus problemas ou criar novas oportunidades". Tais inovações são guiadas mais por mudanças de comportamento do que por mudanças tecnológicas ou de mercado, geralmente emergindo através de processos organizacionais "de baixo para cima" em vez daqueles de "cima para baixo" (MANZINI, 2014). Para Meroni (2008) é possível identificar através deste movimento a existência de comunidades criativas, pessoas que colaboram na invenção e na sustentação de um processo para soluções viáveis para uma nova forma de vida. Para Manzini (2008), quando tais comunidades evoluem, tornam-se empreendimentos sociais difusos e nos casos promissores tornam-se organizações colaborativas.

Através dos processos do design estratégico, são estabelecidas formas de diálogo entre vários atores que vão engajando-se na construção da inovação. Além disso, atua com sua capacidade de habilitar tais atores ao longo das diferentes etapas de projetação. Para Zurlo (2010), o design estratégico, através de sua atividade de projeto, atua na ativação da ação estratégica dentro das organizações. O design estratégico é, portanto, um fenômeno complexo que se compara com fenômenos complexos: tentar interpretá-lo significa não ceder a intenções simplificadoras (ZURLO, 2010).

Nesse contexto é que os problemas complexos contemporâneos podem ser projetados em estruturas de laboratórios que promovem a inovação social. 0 entendimento comum do conceito de laboratórios, normalmente está pautado na concepção de que são espaços físicos devidamente equipados, cujas atividades ocorrem sob condições ambientais controladas e normatizadas. Um laboratório também é qualquer ambiente aberto para que sejam desenvolvidos 
processos experimentais referentes a alguma área comum de interesse das pessoas. Ou seja, é um espaço que favorece o experimento livre e autônomo e onde se iniciam propostas que, potencialmente, irão tratar de atuar em alguma dimensão maior.

Neste artigo, tais laboratórios referidos estão vinculados a um tipo específico, que são reconhecidos como Living Labs. Para Eriksson, NiitamoVeli e Kulkki (2005), os Living Labs representam uma metodologia de pesquisa centrada no usuário para sentir, prototipar, validar e refinar soluções complexas que envolvam situações da vida real. Embora existam diferentes autores que definem os Living Labs, Bitencourt e Bignetti (2012) apresentam o entendimento como um ambiente estruturado em uma rede de inovação social constituída por atores da sociedade civil, autonomamente ou em parceria com o poder público, atuando em conjunto com os interessados na co-criação e no desenvolvimento de novas soluções, novos serviços ou novos modelos de negócios sustentáveis (BITENCOURT E BIGNETTI, 2012). Os Living Labs podem ser tanto uma organização facilitadora de processos de inovação quanto espaços físicos onde as pessoas experimentam essas novas soluções. Segundo Manzini (2008), por organização facilitadora entende-se aquelas que habilitam processos de inovação. Esse movimento é o que Zurlo (2004) reconhece como a necessidade de um processo experimental inacabado que prototipa soluções para os mais diferentes contextos.

Ouden (2012) apresenta o desenvolvimento de inovação transformacional a partir da criação de valor compartilhado em quatro níveis: usuário, organizações, ecossistema e sociedade. A atividade dos Living Labs pretendem ir ao encontro desse tipo de inovação. Para uma inovação ser bem sucedida deve melhorar a qualidade de vida da sociedade como um todo (OUDEN, 2012).

O dinamismo implicado nesse processo, possui uma nítida orientação para processos de inovação. Os Living Labs como organizações facilitadoras, promovem a visualização de novas oportunidades a partir do envolvimento direto das pessoas e das comunidades. Uma possibilidade é a construção de cenários futuros, orientada pelas capacidades do design.

A partir do prévio entendimento sobre os Living Labs, é possível perceber que a sua função aproxima-se sensivelmente ao metadesign. Para Giaccardi (2005), o metadesign transforma culturalmente o sentido do design como semeadura, ao invés do design como planejamento. Traz consigo a possibilidade de projetar algo que vai surgir, enquanto o planejamento busca um controle maior das variáveis. O metaprojeto através de sua processualidade de projeto também pode ser compreendido como uma atividade de cunho estratégico.

A necessidade de elaborar uma estratégia projetual adequada, transfere uma responsabilidade significativa para aquele que facilita a construção desses cenários. Segundo Franzato (2011), os cenários podem ser percebidos como uma metodologia voltada para a preparação de pesquisas preparatórias ao projeto. 0 domínio de diferentes ferramentas para a projetação possibilita a condução do processo com uma maior fluidez. O metaprojeto nasce, portanto, da necessidade de existência de uma "plataforma de conhecimentos" que sustente e oriente a atividade projetual em um cenário dinâmico (DE MORAES, 2010). 
Sendo assim, este artigo pretende elaborar uma reflexão teórica acerca da relação existente entre o metaprojeto e os Living Labs. O metaprojeto como uma possibilidade de habilitação aos processos do design estratégico. Sua orientação para uma prospecção de novos resultados estabelece bases projetuais na medida em que avança em seu processo reflexivo. Logo, a processualidade implícita a partir das atividades que os Living Labs articulam com as pessoas e comunidades, levam a crer na sua aproximação com o metaprojeto.

\section{LIVING LABS}

Os Living Labs são metodologias de investigação centradas no usuário. Para Pinto e Fonseca (2013), tais estruturas transferem a responsabilidade e o controle da inovação para as mãos dos cidadãos. Portanto, podem ser compreendidos com um sistema aberto que articula processos de inovação. A origem do conceito na década de noventa está associado ao arquiteto William J. Mitchell do MIT (Massachusetts Institute of Tecnology). O pesquisador pretendia estabelecer uma forma que incluísse o usuário na construção de soluções para os desenhos da cidade.. A preocupação justitifica-se pelo fato das pessoas representarem, em primeira instância, os usuários reais das estruturas urbanas. $\mathrm{O}$ primeiro experimento realizado pelo arquiteto, segundo Bitencourt e Bignetti (2012), já apontava uma orientação para construção de cenários futuros na observação do padrão de vida de usuários de uma casa inteligente projetada para um período futuro. Logo, identifica-se uma coerência fundante que reconhece o usuário como agente central na construção da inovação.

Segundo o que apresenta Eriksson, NiitamoVeli e Kulkki (2005), os Living Labs também podem ser compreendidos a partir de quatro principais atividades: co-criação, exploração, experimentação e avaliação. Cada uma dessas atividades configuram ambientes de experimentação, nos quais são co-criados processos de inovação. A exploração refere-se na descoberta de usos, comportamentos e oportunidades de mercado emergentes. A implementação de cenários vivos dentro das comunidades de usuários fica por conta da atividade de experimentação. Nota-se que os processos são produzidos a partir da interação criativa entre os usuários. A atividade de avaliação olha para os conceitos elaborados, produtos e serviços em uma perspectiva que amplia sua percepção de valor.

A partir das suas principais atividades, os Living Labs permitem que problemas complexos sejam identificados e habilitem o desenvolvimento de soluções aceitáveis para uma gama de usuários finais (GRAY; MANGYOKU; SERRA; SÁNCHEZ; ARAGALL, 2014). No entanto, a metodologia que sustenta a projetação desse processo é fundamental. A inovação orientada pelo design aproxima o usuário do processo de inovação. Amplia-se consideravelmente o significado do resultado final, porque é mais provável que satisfaça suas necessidades. Ao mesmo tempo, entende que todas as pessoas assumem um papel de projetistas, mesmo que não tenham experiência de designer.

Para Serra (2010), os Living Labs podem assumir duas diferentes configurações: aqueles que ajudam as empresas a conectar-se com as demandas de seus usuários, facilitando processos de desenvolvimento de novos produtos 
ou serviços, e aqueles que concentram-se em abrir os sistemas de inovação a todos os cidadãos, chamados de laboratórios cidadãos. A partir das contribuições de Pinto e Fonseca (2013), também é possível identificar três tipos diferentes de Living Labs. O primeiro tipo são espaços físicos que funcionam como residências temporais para pessoas que experimentam novas tecnologias (PINTO; FONSECA, 2013). O segundo tipo são as organizações facilitadoras de processos de inovação através de metodologias de co-criação com os usuários. O terceiro tipo são os Living Labs que configuram-se como rede de inovação, sendo toda a rede compreendida como Living Labs.

A partir da consulta ao site oficial da ENoLL (2015), percebe-se que os Living Labs estruturaram-se inicialmente através desta rede europeia que congrega diversos laboratórios no mundo. Sua função política é promover um ambiente amplo de fomento aos processos de inovação desenvolvidos pela rede de laboratórios filiados. A ENoLL oferece serviços de desenvolvimento de projetos, favorecendo através do seu endosso como instituição, a submissão de propostas à convocatórias de projeto diversas. Além disso, promove atividades formativas de diferentes assuntos relacionados com a temática de inovação. Uma de suas funções é exercer a função de intermediador entre os diferentes Living Labs cadastrados na rede. A ENoLL disponibiliza um serviço de aproximação entre seus membros e serve como um balcão de negociação para novos projetos. Funciona como uma instituição que abre novas perspectivas para seus membros. Ela promove uma busca das melhores oportunidades para que prospere os Living Labs que demandam por novas alianças, parcerias ou fundos de investimento.

No contexto Brasil, existem diferentes perfis de Living Labs cadastrados na ENoLL. Basicamente os tipos dois e três apresentados anteriormente, são aqueles que podem ser reconhecidos no Brasil. Para Pinto e Fonseca (2013), a maior motivação dos Living Labs nacionais terem buscado o credenciamento é a possibilidade de conseguirem recursos financeiros para seus projetos. Além disso, o tipo de instituição que abriga os Living Labs nacionais também é diversificada. Percebe-se a existência de Organismos Públicos, ONG, Fundação Privada, Empresas Privadas e Universidade. Em seu estudo que apresenta os Living Labs brasileiros, Pinto e Fonseca (2013) demonstram que estão organizados por projetos de natureza diversa. Identifica-se, portanto, uma nítida orientação pela prática projetual dentro desse contexto.

\section{METAPROJETO}

A geração de inovação orientada pelo design requer o entendimento de dois processos distintos. Trata-se do projeto e do metaprojeto. O projeto é o modo pelo qual se organizam os fatores que concorrem para obter um resultado (CELASCHI, 2007). É nesta etapa de projetação que elabora-se uma observação e um contato muito próximo com a realidade. Também compreende-se a definição de um problema para que seja possível a construção da solução. Por outro lado, Celaschi (2007) demonstra que metaprojeto é o espaço que trabalha com a programação do processo de pesquisa e projetação que pretende-se utilizar. É através do metaprojeto que podem ser criados artefatos que ampliam as possibilidades da projetação. A metaprojetação é, portanto, uma ação muito 
delicada (CELASCHI, 2007). O entendimento de programação sugere um processo mais controlado e previsível. A visão desse autor a respeito de metaprojeto contrapõe a operação imprevisível que a processualidade percorrerá.

Já Franzato (2014) apresenta o deslocamento da realidade como um dos princípios que orienta a ação metaprojetual. Semanticamente, o principal significado da palavra meta, quando utilizado como prefixo, é a mudança de lugar, de ordem ou de natureza (GIACCARDI, 2005). Tal movimento implica em uma operação que possibilita a criação de novas estruturas não apenas voltado para um, mas para diversos projetos que poderão existir. A reflexão do deslocamento poderá partir no exercício do projeto, entretanto poderá levar a percepções que ampliarão do projeto. Converte-se, portanto, como conhecimento de processo e como riqueza de informação, qualifica o processo de inovação de forma evidente (CELASCHI, 2007).

Um segundo princípio importante é a abertura que deve possibilitar durante o processo metaprojetual. Para Giaccardi (2005), deve permitir uma dinâmica relacional que comporte a construção de sistemas baseados em processos abertos que afetem e sejam afetados, simultaneamente. Restringir a percepção daquilo que apresenta-se como novo é um equívoco na ação metaprojetual. Ao contrário de limitar o campo da visão, deve operar na sustentação do estado de abertura constante.

Ao encontro das contribuições de Giaccardi, De Mul (2011) amplia a reflexão teórica ao sugerir uma atuação do designer como um metadesigner. Um metadesigner que projeta um espaço multidimensional que tenha uma interface amigável, permitindo que o usuário converta-se em um co-desiner, mesmo quando esse usuário não tenha experiência de designer ou nenhum tempo para ganhar essa experiência através da tentativa e erro (DE MUL, 2011). No plano metaprojetual, contudo, o co-design é percebido no sentido de permitir o envolvimento, a interação ou a participação. Tal colocação favorece uma leitura a respeito dos processos que envolvem o metadesign.

Um dos processos que é possível descrever é a sua capacidade habilitante na elaboração de plataformas, sistemas, infraestruturas ou contextos. Percebese uma relação desse processo com o princípio da abertura já mencionado. Para Manzini (2008), as plataformas habilitantes, muitas vezes, servem como suporte para as diferentes organizações colaborativas. $O$ autor apresenta os conceitos de espaços flexíveis e espaços experimentais como exemplos de plataformas habilitantes. Os espaços flexíveis podem ser utilizados por comunidades em um "mix" de funções públicas e privadas, respondendo de modo inovador a demandas por espaço e abrigo (MANZINI, 2008). Por outro lado, os espaços experimentais podem ser compreendidos não apenas como incubadores de negócios sociais, mas também concebem experimentações. O processo de semeadura, no sentido de promover algo que irá surgir, pode ser compreendido como uma operação metaprojetual. A metáfora é inerente ao processo de uma plantação. É no ato da semeadura que deposita-se o esforço para algo que não é sabido o que virá. Essa operação metaprojetual aproxima-se do funcionamento de uma plataforma habilitante. É através dela que a projetação recebe o amparo que levará ao surgimento de tantos novos projetos. 
Além disso, a elaboração de cenários também é um processo de metaprojeto que tem como objetivo ir ao encontro da inovação. É através dos cenários que identifica-se caminhos para inovação. Para Manzini e Jégou (2004), a construção de cenários inclusive requer uma variedade de ferramentas conceituais e operacionais que serão utilizadas na facilitação ao longo do processo.

A construção de cenários implica em três elementos fundamentais: uma visão, uma razão de ser, e algumas propostas práticas que, em conjunto constituem a arquitetura cenário (MANZINI, JÉGOU, 2004:136). A visão, é a parte mais específica de um cenário. É através dela que busca-se uma resposta imaginativa ou projetiva. Aqui percebe-se um dos princípios do metaprojeto que é o deslocamento da realidade. A razão de ser de um cenário, ou sua justificativa, opera na sua existência e confere o seu significado. Busca responder a relevância do cenário. A praticabilidade de um cenário é o elemento que acrescenta profundidade e consistência para a visão.

Os cenários promovem formas de inovação de um sistema. É voltado para processos futuros ou uma inovação sistêmica. Também podem ser entendidos como a imaginação de alternativas, logo trata-se de um exercício de visão e prospecção dessas alternativas e tentativas de alcance voltadas às alternativas. Os propósitos da utilização de cenários são os mais diversos, no entanto, aplicam-se em geral, em situações de difícil previsão (REYES, 2010). A ponderação que Hindrichson e Franzato (2012) fazem a respeito do grau de incerteza vinculado a um projeto, leva à reflexão sobre a função do pensamento por cenários. Em um contexto instável e imprevisível, os cenários podem ser percebidos como uma orientação que está entre a zona de ação as intenções projetuais. Além disso, possibilita a reprojetação dos processos de projeto.

Sendo assim, os Living Labs aproximam-se do metaprojeto a partir da representação de suas características e funções. São espaços que devem permitir uma projetação conjunta que atenda as necessidades da vida cotidiana dos usuários. Podem ser, inclusive, reconhecidos como sistemas de conexão capazes de interligar melhor as pessoas (MANZINI, 2008). Como plataforma habilitante, portanto, os Living Labs assim como o metaprojeto constituem-se pela abertura dos seus processos. Tal movimento de abertura, constitui a facilidade que os usuários encontram através da interação com os Living Labs. É um ambiente que trabalha na articulação de vínculos e desejos de ações inovadoras.

Os processos de metadesign atuam diretamente relacionados com a dinâmica dos Living Labs. Fica nítida a comparação entre as plataformas habilitantes representadas como os espaços flexíveis e espaços experimentais com os Living Labs apresentados. Não apenas uma comparação, mas a qualificação no entendimento dos Living Labs. Percebe-se um significado em relação ao espaço e sua importância para a geração de novos projetos inovadores. Funcionam como pontos de encontro para projetação orientada pelos desejos de inovação que pretendem atuar. Ainda que não houve um aprofundamento em relação ao espaço físico em si, cabe um melhor entendimento se há uma influência dos elementos do espaço nos processos de inovação. 


\section{CONSIDERAÇÕES FINAIS}

Os Living Labs, como organizações facilitadoras de processos de cocriação, atuam através da interação entre os usuários. Retomando Ouden (2012), é importante para uma organização encontrar uma proposição de valor deixando-a clara para os seus usuários. Sendo assim, identifica-se que os Living Labs chamados como laboratórios cidadão, necessariamente, devem preocuparse na forma como abrem seu sistema de inovação. Nesse sentido, o processo metaprojetual do co-design em Living Labs, requer um trabalho para deixá-lo mais tangível aos usuários. Embora represente um processo bastante claro de operação metaprojetual, deve ser percebido pelos usuários, principalmente, em espaços físicos que não possuem uma organização facilitadora dos processos de co-criação.

Cabe elucidar que a processualidade derivada do funcionamento dos Living Labs apresenta uma correlação com a inovação social. Identifica-se um aspecto pertinente que amplia uma percepção a respeito disso. Segundo as contribuições de Ouden (2012), um processo de inovação deve buscar a geração de valor não apenas para o usuário, mas para a sociedade como um todo. 0 propósito da inovação social é ocupar a lacuna de espaço daquilo que se tem hoje, para o que as pessoas querem e o que é oferecido por governos, empresas privadas ou organizações não governamentais (OUDEN, 2012).

Os Living Labs, portanto, podem atuar como organizações facilitadoras de processos de co-criação. Como já visto, não apenas na projetação, mas também ocupam a função da metaprojetação. A inspiração através do desenvolvimento dos projetos no dia a dia pode disparar um processo metaprojetual. $\mathrm{O}$ ineditismo dispara uma reflexão metaprojetual durante o processo de projeto. Embora sejam duas situações diferentes, não ocorrem em perspectivas cronológicas diferentes necessariamente.

Por fim, percebe-se que os processos do design estratégico conseguem exercer sua atividade através dos Living Labs. A maneira como essas estruturas habilitam a conexão e a criação aberta de novos projetos, permitem a interpretação que articula sua proximidade invariável com o metaprojeto. A processualidade envolvida nos Living Labs, ainda que constantemente revisitada por excelência, carrega uma nítida relação com as operações metaprojetuais.

\section{REFERENCIAS}

BITENCOURT, Silvio; BIGNETTI, Luiz. (2012): “A Inovação Social e a Dinâmica de Inovação Aberta na Rede Brasileira de Living Labs". XXXVI Encontro da ANPAD, Rio de Janeiro.

CELASCHI, F. Dentro al progetto: appunti di merceologia contemporanea. In: CELASCHI,F.; DESERTI, A. Design e innovazione: strumenti e pratiche per la ricerca applicata. Roma:Carocci Editore, 2007, pp. 15-38

DE MUL, J. Redesigning design. In: VAN ABEL, B. et al. (org.). Open Design Now: Why Design Cannot Remain Exclusive. Amsterdam: BIS publishers, 2011.

ERIKSSON, M.; NIITAMO VELI, P. y KULKKI, S. (2005): "State-of-the-art in utilizing Living Labs approach to user-centric ICT innovation-an European approach".

Technology, vol.1, no 13, pp. 1-13. 
European Network of Living Labs (ENoLL). CIDADE, 2015. Disponível em: http://www.openlivinglabs.eu/. Acesso em 10/06/2015

FRANZATO, C. O princípio de deslocamento na base do metadesign. In: 11응 Congresso Brasileiro de Pesquisa e Desenvolvimento em Design, 2014, Gramado. Anais. São Paulo:Editora Edgard Blücher, 2014, p. 1187-1196.

FRANZATO, C.; CELASCHI, F. Processo de metaprojeto para o desenvolvimento estratégico e a inovação das organizações. In: X P\&D Design - Congresso Brasileiro de Pesquisa e Desenvolvimento em Design, 2012, São Luís. Anais... São Luís: EDUFMA, 2012. p. 1-14.

GIACCARDI, E. Metadesign as an Emergent Design Culture. Leonardo, v. 38, n. 4, 2005, p. 342-349.

GRAY, M., MANGYOKU, M., SERRA, A., SÁNCHEZ, L., \& ARAGALL, F. 2014. Integrating Design for All in Living Labs. Technology Innovation Management Review, 4(5): 50-59. http://timreview.ca/article/793.

HARTMANN, P.; FRANZATO, C. Design de cenários: uma tecnologia para promover o compartilhamento de conhecimentos em redes de projeto. Revista D: Design, Educação, Sociedade e Sustentabilidade, v. 4, n. 4, 2012, pp. 155-168. OUDEN, Elke. Innovation Design: creating value for people, organizations and society. London: Springer Verlang, 2012.

STEEN, M., MANSCHOT, M., \& DE KONING, N. (2011). Benefits of co-design in service design projects. International Journal of Design, 5 (2), 53-60.

MANZINI, Ezio. Strategic Design for Sustainability: instruments for radically oriented innovation. In: JÉGOU, F; MANZINI, E. Sustainably everyday: scenarios of urban life. Milano: Edizioni Ambiente, 2003

MANZINI, Ezio. Design para a inovação social e sustentabilidade: comunidades criativas, organizações colaborativas e novas redes projetuais. Rio de Janeiro: Epapers, 2008. (Cadernos do Grupo de Altos Estudos; v.1)

MANZINI, Ezio. Making Things Happen: Social Innovation and Design. Design Issues: v.30 n.1, 2014.

MERONI, Anna. Strategic design: where are we now? Reflection around the foundations of a recent discipline. Strategic Design Research Journal, v.1, n.1, Dec 1, p.31-38. 2008.

MORIN, E. A complexidade e a ação. In: MORIN, E. Introdução ao pensamento complexo. Porto Alegre: Sulina, 2011.

DE MORAES, D. Conceito. In: DE MORAES, D. Metaprojeto: o design do design.São Paulo: Blücher, 2010.

PINTO, Miriam M.P.; FONSECA, Leticia P. (2013): Profundizando la comprensión de los Living Labs de Brasil, Revista CTS, n 23, vol 8, 2013.

REYES. Paulo (2010): Construção de cenários no design: o papel da imagem e do tempo. 9 Congresso Brasileiro de P\&D em Design.

SERRA, A. (2010): “Citilabs: ¿Qué pueden ser los laboratorios ciudadanos?”, Revista La Factoría, vol. 45-46.

VERGANTI R. Design, Meanings, and Radical Innovation : A Metamodel and Research Agenda. The Journal of Product Innovation Management, 2008.

ZURLO, Francesco. Design Strategico. In: XXI Secolo, vol. IV, Gli spazi e le arti. Roma: Enciclopedia Treccani. 2010. 
UNCED. United Nations Conference on Environment and Development, Rio deJaneiro, 3-14 jun. 2006. The Rio Declaratiom on Environment and Development.

em: http://www.onu.org.br/rio20/img/2012/01/rio92.pdf Acessado em: 30 Ago. 2015. 